\title{
The Effect of Nebulized Salbutamol on Serum Potassium and Blood Sugar Level of Asthmatic Patients
}

\author{
Omar Farooq Nafea Al-Azzawi ${ }^{1}$, Muhammed Waheeb Al. Obaidy ${ }^{1} \&$ Doaa Mohammed Shihab ${ }^{2}$ \\ ${ }^{1}$ Department of Medicine, College of Medicine, University of Baghdad, Baghdad, Iraq \\ ${ }^{2}$ Department of Emergency and Critical Care, Baghdad Teaching Hospital, Medical city, Baghdad, Iraq \\ Correspondence: Omar F Al-Azzawi, Department of Medicine, College of Medicine, University of Baghdad, \\ Baghdad, Iraq. E-mail: omarazawi108@yahoo.com
}

Received: June 30, 2018 Accepted: July 24, 2018 Online Published: August 1, 2018

doi:10.5539/gjhs.v10n9p25 URL: https://doi.org/10.5539/gjhs.v10n9p25

\begin{abstract}
Background: Nebulized Salbutamol have great advantages for patients with respiratory problems by depositing drugs directly to the lungs, inspite of reported adverse metabolic effects on different electrolytes and glucose heamostasis of patients.

Aim of Study: To evaluate the effect of nebulized salbutamol used in the management of patients with asthma who have normal serum potassium and blood glucose levels. in the emergency department after 30 and 60 minutes of administration and to find out if these results are of clinical importance that should be taken in consideration when treating patients especially those with abnormal glucose hemostasis or electrolyte disturbance.
\end{abstract}

Patients and Methods: The study is a prospective follow up study conducted in Emergency Department of Baghdad Teaching Hospital through the period from $1^{\text {st }}$ of April, 2017, to $31^{\text {st }}$ of January, 2018 on a sample of 100 patients. After administration of nebulized salbutamol, the Potassium and Glucose levels of patients were assessed in three periods; baseline, after 30 minutes and after one hour.

Results: The potassium mean was significantly decreased after 1 hour of nebulizer administration $(\mathrm{p}<0.001)$. The random blood sugar mean was significantly increased after 1 hour of nebulizer administration $(p<0.001)$. The potassium level was significantly decreased one hour after nebulizer administration for patients with negative steroids history $(\mathrm{p}=0.03$ ), while no significant difference in potassium level was observed for patients with positive steroids history.

Conclusions: The nebulizer applying salbutamol has a profound effect in lowering the Potassium level and increasing blood glucose level after 60 minutes of administration.

Keywords: effect, nebulized, salbutamol, blood sugar, serum potassium

\section{Introduction}

Nebulizers are inhalation devices that use oxygen, compressed air, or ultrasonic power to break up solutions or suspensions of medication into droplets for inhalation. The aerosol is administered by a mask or mouthpiece. However, nebulizers are more expensive than pressurized metered dose inhalers, require a power source, and need regular maintenance (Wright et al., 2002). From the historical and medical point of view, a Greek, called Pedanus Discorides during the first century prescribed inhaled fumigation. Pipes were also used to inhale hallucinogenic substances by Red Indians who knew the psychotropic effects of poisonous plants such as Datura stramonium, and used fumigations of Datura ferox to treat asthma. Since the nineteenth century, Datura stramonium was imported in Great Britain and cigarettes with leaves of datura were used by asthmatics until 1992. By 1949, ultrasonic nebulizers made their first appearance in the United States, in the form of humidifiers, and then doctors were quick to add medications to produce therapeutic aerosols (Dessanges et al., 2001). The main advantage of nebulized drugs is that they are deposited directly into the respiratory tract and thus a higher drug concentration can be achieved in the bronchial tree and pulmonary bed with fewer adverse effects than when the systemic route is used. The effectiveness of nebulization depends on many factors, including the characteristics of the drug to be nebulized (particle size, form, density, and surface tension), the anatomy of the airways, the patient's inhalation technique and the nebulization system employed. The factors determining the particle size produced by a nebulizer include both the characteristics of the solution and the flow velocity of the nebulization system. Particles of 
between 1 and $5 \mu \mathrm{m}$ are those with the greatest probability of reaching the site desired in the bronchial tree and of achieving the desired therapeutic effect (Máiz et al., 2011). There are three main types of nebulizers: ultrasonic, jet and mesh nebulizers. Of the three, the most effective are mesh nebulizers. These nebulizers are also the most compact, quietest and most rapid, leading to a better patient responsiveness (Ari, 2014).

Indications of nebulization are; to deliver bronchodilator drugs in an acute attack of asthma and/or COPD and nebulization is the most common means of delivery, to administer antibiotics and anti-fungal agents in some resistant cases or persistent chest infections for eg. Cystic fibrosis, to aid expectoration by inhalation of hypertonic saline which increase the clearance of bronchial secretions and finally to deliver a local analgesia: to relieve symptoms as in patients with alveolar carcinoma (Ari, 2014).

B2-adrenoceptor agonists (B2AR): Airway tone is predominantly controlled by parasympathetic stimulation carried by the vagus nerve which provides baseline tone of the airway smooth muscle (ASM). Parasympathetic innervations, primarily via cholinergic fibers, activate muscarinic receptors to control ASM tone and respiratory microvasculature. In doing so, parasympathetic stimulation mediates the bronchodilatory process by inhibiting dilation and inducing contraction of ASM. The sympathetic nervous system does not directly innervate ASM but does innervate airway vasculature and parasympathetic ganglia. Sympathetic adrenergic nerves regulate airway function indirectly via the adrenergic catecholamines which act on $\alpha$ - and $\beta$-adrenoceptors. Conventionally, $\beta 2 \mathrm{AR}$ agonists are divided into two groups according to the duration of action: short-acting (3-6 hours) and long-acting ( $\sim 12$ hours) $\beta 2 \mathrm{AR}$ agonists, abbreviated as S $\beta 2 \mathrm{ARs}$ agonists and L $\beta 2 \mathrm{ARs}$ agonists, respectively (Cazzola et al.,2012). Salbutamol, a S $\beta 2 A R$ agonists, enters the active site of the $\beta 2 A R$ directly leading to rapid bronchodilation time ( $<5$ minutes) followed by rapid re-equilibration that results in a short duration of action (4-6 hours) (Johnson et al.,2001). There may be a dose-response relationship with salbutamol inhalation such that a larger dose $(1600 \mu \mathrm{g})$ may have a longer duration of action than a smaller one $(200 \mu \mathrm{g})$ (Cazzola et al.,2011).

Systemic bioavailability of inhaled drugs arises from absorption through the gastrointestinal tract as well as the lungs. Upon administration, a fraction of the inhaled drug will be deposited in the oropharynx and absorbed directly into the systemic circulation. Although a portion of the dose reaches the stomach and intestine, this fraction undergoes extensive first-pass metabolism and is essentially rendered inactive (Bennett et al., 2000).

Due to the widespread distribution of $\beta 2 A R s$ throughout the body some side effects following $\beta 2 A R$ agonist administration are considered inevitable. These side effects are greatest when $\beta 2 \mathrm{AR}$ agonists are administered orally or via injection. The pharmacological effects can be circumvented, though not entirely; when the systemic load (plasma concentration) is reduced; by introducing the drugs via inhalation and/or in the recommended dose. These side effects include muscle tremor, increased blood insulin, glucose, lactate, fatty acid, and glycerol, decreased serum potassium and calcium, increased intracellular potassium, alterations in skeletal and cardiac muscle function, tachycardia, vasodilatation, appetite suppression, headache, nausea, hyperactivity (children) and sleep disturbances (Sears \& Lötvall,2005).

Adrenergic stimulation of cardiac $\beta 2$ ARs modulates the heart rate and contractility of the heart. In skeletal muscle, the effects of $\beta 2 A R s$ stimulation are through a G-protein activation of adenyl cyclase which leads to elevation of cAMP and subsequent activation of protein kinase (PKA). PKA catalyzes the phosphorylation of a number of receptors within the myocytes, including ryanodine receptors and troponin, leading to increased contractility. Membrane channels and binding proteins are phosphorylated by PKA in pacemaker cells which leads to changes in the cardiac action potential through increased $\mathrm{Ca}^{2+}$ cycling (Tank \& Lee, 2015; Hostrup et al., 2014).

Activation of glycogen phosphorylase, phosphofructokinase, pyruvate dehydrogenase, and hormone-sensitive lipase increases substrate utilization in skeletal muscle. Furthermore, $\beta 2 \mathrm{AR}$ stimulation of the $\mathrm{Na}+/ \mathrm{K}+-\mathrm{ATPase}$ pump increases intracellular concentrations of potassium and hyperpolarization of the cellular membrane. The activation of this pump consumes ATP, leading to ADP production that further drives glycolysis, resulting in increased lactate production (Andersson et al., 2012; Kalsen et al., 2014; Levy et al., 2008).

$\beta 2 \mathrm{AR}$ agonists are known to increase membrane $\mathrm{Na}+/ \mathrm{K}+$ ATPase activity, thereby increasing intracellular $[\mathrm{K}+]$, decreasing intracellular $\left[\mathrm{Na}^{+}\right]$, and maintaining membrane excitability and hyperpolarizing the sarcolemma (Clausen, 2003). The decrease in serum potassium is dose-related and potency-related, with some $\beta 2 \mathrm{AR}$ agonists having a more profound hypokalemic effect than other $\beta 2 \mathrm{AR}$ agonists, with fenoterol having a more profound hypokalemic effect than albuterol or formoterol or terbutaline. Also the $\beta 2 \mathrm{AR}$ agonists increase glycogenolysis and hence increase plasma glucose. This is of minor clinical importance, except in diabetic patients, whose disease is likely to be aggravated by the use of systemic corticosteroids in situations of severe asthma. The effect on glucose also shows tolerance with repeated use (Ouf et al., 2015; Sears, 2002). 
Seventy five deaths of asthmatic patients in a recent study using home nebulizers were reported, $16-30 \%$ of them had delay in seeking help, because of over reliance on high doses of salbutamol. The exact mechanism of death in such cases is unknown, but has been postulated to be due to fatal cardiac arrhythmias induce by hypoxia (Holt, 2007), an alternative hypothesis is that inhalation of high dose beta2-agonist induced hypokalemia may further aggravated by the acute stress of the illness and by concomitant corticosteroids or theophylline therapy, so accurate detection of this side effect is useful (Scichilone et al., 2015). There are several studies that demonstrate a statistically significant decrease in serum potassium and magnesium after $\beta 2 \mathrm{AR}$ agonists administration. In addition, there are also some studies regarding the $\beta 2 \mathrm{AR}$ agonists induced hypophosphatemia (Sahan et al., 2013).

Aim of the study is to evaluate the effect of nebulized salbutamol used in the management of patients with asthma who have normal serum potassium and blood glucose levels. in the emergency department after 30 and 60 minutes of administration and to find out if these results are of clinical importance that should be taken in consideration when treating patients especially those with abnormal glucose heamostasis and/or electrolyte disturbances.

\section{Patients \& Methods}

The study is a prospective follow up study conducted in the Emergency Department (ED) of Baghdad Teaching Hospital through the period from $1^{\text {st }}$ of April, 2017, to $31^{\text {st }}$ of January, 2018. A total of 100 patients were recruited for the study after fulfilling the inclusion and exclusion criteria.

\subsection{Inclusion Criteria}

All adult patients with mild exacerbation of asthma who needed two doses of $2.5 \mathrm{mg}$ nebulized salbutamol, 10 minutes apart for the relief of their symptoms is included.

\subsection{Exclusion Criteria}

1) Patients who used $\beta 2 A R$ less than four hours before admission.

2) Recent cardiac event (MI, angina or cardiac arrythmia).

3) Diabetic patients or abnormally high blood glucose at base line level.

4) Abnormally high serum potassium at base line.

5) Patients with severe dyspnea and/or respiratory failure.

6) Patients with renal failure.

7) Patients using potassium sparing diuretics e.g. Aldactone and antihypertensive drugs e.g. B.blocker, ACE inhibitor, Angiotensin II.

\subsection{Data Collection}

The data was collected by the researcher through meeting with the patients and filling a prepared questionnaire paper. After taking a full history, examination and performing the full needed emergency management for all patients, the 100 eligible patients under went;

1) A $5 \mathrm{ml}$ sample of venous blood was taken and sent to the Laboratory of Baghdad Teaching Hospital to evaluate the $\mathrm{S}$ potassium and random blood sugar levels (Baseline level).

2) Then the selected patients were treated with $2.5 \mathrm{mg}$ nebulized Salbutamol, while the patient was in a sitting upright position and the mask of the nebulizer was held on the nose. The nebulizer equipment used was Mesh ROSSMAX ${ }^{\circledR}$ nebulizer.

3) After 20 minutes the second dose of $2.5 \mathrm{mg}$ nebulized Salbutamol was given through the nebulizer in the same way for the patients who needed this $2^{\text {nd }}$ dose and so the total dose used was $5 \mathrm{mg}$ only, as we only recruited mildly dyspneic patients to decrease the chance of using other agents that may affect potassium and glucose level.

4) Thirty minutes after nebulizer cessation, $5 \mathrm{ml}$ of venous blood was drawn and sent for the Laboratory to re-check the Potassium and random blood sugar levels (30 minutes level).

5) One hour later, after nebulizer cessation, another $5 \mathrm{ml}$ of venous blood was drawn and sent for the Laboratory to re-check the Potassium and random blood sugar levels (One hour level).

\subsection{Ethical Considerations}

1) Ethical approval was taken from Arab Board for Health Specialties and hospital authorities.

2) Confidentiality was taken in consideration. 
3) An oral informed consent was taken from studied patients.

\subsection{Statistical analysis}

All patients' data entered using computerized statistical software; Statistical Package for Social Sciences (SPSS) version 20. Descriptive statistics presented as (mean \pm standard deviation) and frequencies as percentages. Multiple contingency tables conducted and appropriate statistical tests performed, Chi-square used for categorical variables (Fishers exact test was used when expected variables were less than 5) and one way ANOVA analysis was used to compare between more than two means. In all statistical analysis, level of significance ( $p$ value) set at $\leq 0.05$ and the result presented as tables and/or graphs.

\section{Results}

A total of 100 patients fulfilling the inclusion and exclusion criteria were included in this study. Their mean age is $44.5 \pm 12.5$ years; $13.1 \%$ of them were in the age group $<30$ years, $16.2 \%$ in the age group $30-39$ years, $31.3 \%$ in the age group $40-49$ years, $27.3 \%$ in the age group $50-59$ years and $12.1 \%$ in the age group $\geq 60$ years. Females were more than males with female to male ratio of 1.12:1 (Table 1).

Table 1. Demographic characteristics of patients

\begin{tabular}{lll}
\hline Variable & No. & $\mathbf{\%}$ \\
\hline Age mean \pm SD $(\mathbf{4 4 . 5} \pm \mathbf{1 2 . 5}$ years $)$ & 13 & 13.1 \\
$<30$ years & 16 & 16.2 \\
$30-39$ years & 31 & 31.3 \\
$40-49$ years & 27 & 27.3 \\
$50-59$ years & 12 & 12.1 \\
$\geq 60$ years & 100 & 100.0 \\
Total & & \\
\hline Gender & 47 & 47.0 \\
Male & 53 & 53.0 \\
Female & 100 & 100.0 \\
Total & & \\
\hline
\end{tabular}

The medication history of the studied sample admitted to the ED was: no medication history (24\%). while those with positive medication history was distributed as follows; prednisolone tablets and salbutamol inhalers (49\%), salbutamol inhalers alone (22\%), Inhaled salbutamol and steroids (3\%), (Table 2).

Table 2. Distribution of medications history of patients

\begin{tabular}{lll}
\hline Variable & No. & \% \\
\hline Medications history & & \\
No medication history & 24 & 24.0 \\
Prednisolone tablets and salbutamol inhaler & 47 & 47.0 \\
Salbutamol inhalers & 25 & 25.0 \\
Inhaled salbutamol and steroids & 4 & 4.0 \\
Total & 100 & 100.0 \\
\hline Steroids history & & \\
Positive & 51 & 51.0 \\
Negative & 49 & 49.0 \\
Total & 100 & 100.0 \\
\hline
\end{tabular}


The potassium mean was significantly decreased after 1 hour of nebulizer administration $(\mathrm{p}<0.001)$. No significant changes in potassium mean were observed between baseline measurement and after 30 minutes measurement $(p=0.1)$, but the potassium mean was not significantly changed between 30 minute measurement and 1 hour measurement $(\mathrm{p}=0.2)$. (Table 3 \& Figure 1).

Table 3. Distribution of potassium mean according to three measurements.

\begin{tabular}{|c|c|c|c|c|}
\hline \multirow{2}{*}{ Variable } & Baseline & After 30 minutes & After 1 hour & \multirow{2}{*}{$\mathbf{P}$} \\
\hline & Mean \pm SD & Mean \pm SD & Mean \pm SD & \\
\hline Potassium & $4.57 \pm 0.68$ & $4.4 \pm 0.68$ & $4.23 \pm 0.69$ & $0.002 * \mathrm{~S}$ \\
\hline \multicolumn{5}{|c|}{ Post hoc test } \\
\hline Potassium & \multicolumn{3}{|c|}{ baseline vs. after $30 \mathrm{~m}$} & $0.1^{\mathrm{NS}}$ \\
\hline Potassium & \multicolumn{3}{|c|}{ baseline vs. after $1 \mathrm{~h}$} & $0.001^{\mathrm{S}}$ \\
\hline Potassium & \multicolumn{3}{|c|}{ after $30 \mathrm{~m}$ vs. after $1 \mathrm{~h}$} & $0.2^{\mathrm{NS}}$ \\
\hline
\end{tabular}

*One way ANOVA test, ${ }^{S}$ Significant.

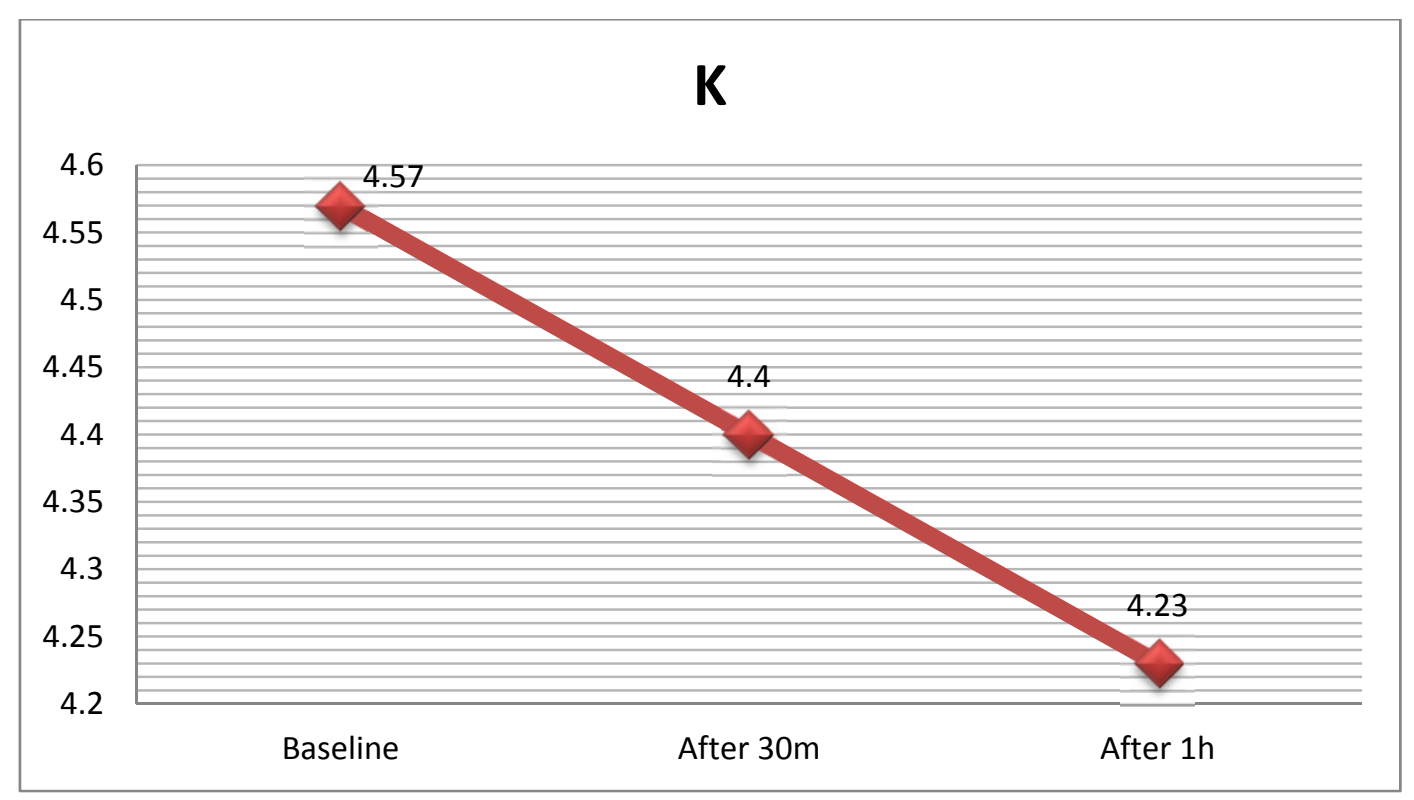

Figure 1. Distribution of potassium mean according to three measurements

The random blood sugar mean was significantly increased after 1 hour of nebulizer administration $(\mathrm{p}<0.001)$. Mean RBS measurement at baseline was not significantly different from RBS measurement after 30 minutes $(p=0.2)$. Similarly, RBS mean was not significantly changed between 30 minute measurement and 1 hour measurement $(\mathrm{p}=0.2)$. (Table 4 \& Figure 2) 
Table 4. Distribution of RBS mean according to three measurements

\begin{tabular}{lllll}
\hline \multirow{2}{*}{ Variable } & Baseline & After 30 minutes & After 1 hour & \multirow{2}{*}{ P } \\
\cline { 2 - 4 } & Mean \pm SD & Mean \pm SD & Mean \pm SD & \\
\hline RBS & $118.7 \pm 18.2$ & $123 \pm 18$ & $127 \pm 18.1$ & $0.006^{* \mathrm{~S}}$ \\
\hline Post hoc test & & & $0.2^{\mathrm{NS}}$ \\
RBS & baseline vs. after 30m & & $0.004^{\mathrm{S}}$ \\
RBS & baseline vs. after 1h & & & $0.2^{\mathrm{NS}}$ \\
RBS & after 30m vs. after 1h & & \\
\hline
\end{tabular}

*One way ANOVA test, ${ }^{\mathrm{S}}$ Significant.

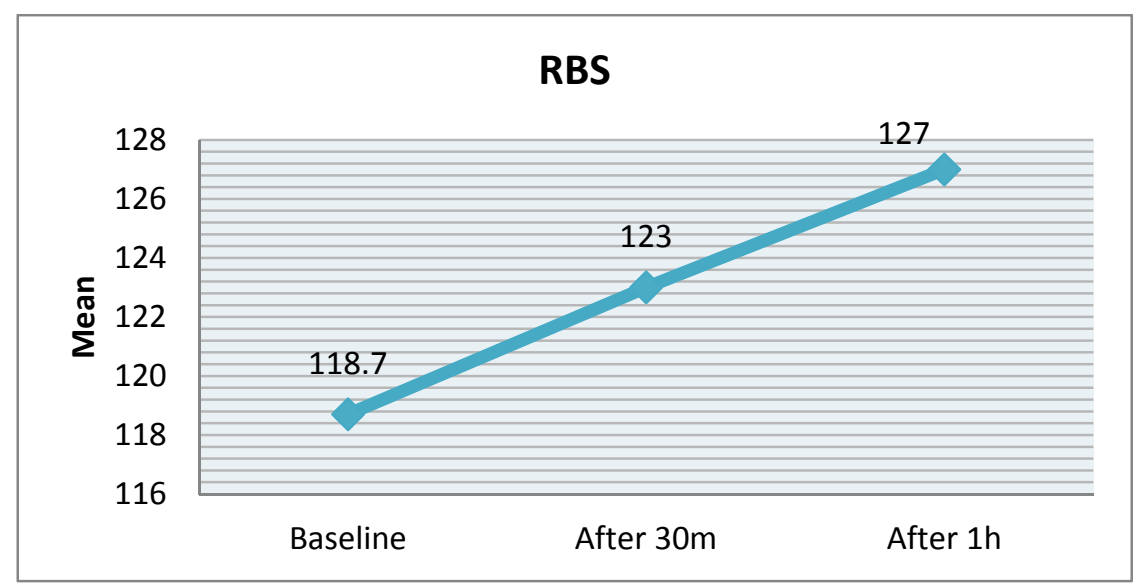

Figure 2. Distribution of RBS mean according to three measurements

Regarding effect of age, no significant effect of age were observed in both the potassium and RBS levels after one hour of nebulizer administration according to different age groups of studied patients, although obvious decrease in potassium level and increase of RBS was noted. (Table 5)

Table 5. Distribution of potassium and RBS means according to three measurements for different age groups

\begin{tabular}{|c|c|c|c|c|}
\hline \multirow{2}{*}{ Variable } & Baseline & After 30 minutes & After 1 hour & \multirow{2}{*}{$\mathbf{P}$} \\
\hline & Mean \pm SD & Mean \pm SD & Mean \pm SD & \\
\hline \multicolumn{5}{|l|}{ Potassium } \\
\hline$<30$ years & $4.62 \pm 0.7$ & $4.46 \pm 0.7$ & $4.3 \pm 0.68$ & $0.5^{* \mathrm{NS}}$ \\
\hline 30-39 years & $4.46 \pm 0.7$ & $4.28 \pm 0.7$ & $4 \pm 0.7$ & $0.3 * \mathrm{NS}$ \\
\hline 40-49 years & $4.5 \pm 0.7$ & $4.34 \pm 0.7$ & $4.17 \pm 0.7$ & $0.1 *^{\mathrm{NS}}$ \\
\hline $50-59$ years & $4.62 \pm 0.67$ & $4.44 \pm 0.64$ & $4.3 \pm 0.64$ & $0.1 *^{\mathrm{NS}}$ \\
\hline$\geq 60$ years & $4.65 \pm 0.57$ & $4.47 \pm 0.55$ & $4.34 \pm 0.57$ & $0.4^{* \mathrm{NS}}$ \\
\hline \multicolumn{5}{|l|}{ RBS } \\
\hline$<30$ years & $120.7 \pm 12.4$ & $123.8 \pm 11.9$ & $126.9 \pm 13.6$ & $0.1^{* \mathrm{NS}}$ \\
\hline 30-39 years & $118.7 \pm 18.2$ & $123 \pm 18$ & $127 \pm 18.1$ & $0.3^{* \mathrm{NS}}$ \\
\hline 40-49 years & $114.8 \pm 20.7$ & $118.8 \pm 19.7$ & $123.5 \pm 19$ & $0.2^{* \mathrm{NS}}$ \\
\hline $50-59$ years & $122.5 \pm 22.7$ & $127.25 \pm 22.7$ & $130.4 \pm 23.2$ & $0.4 *^{\mathrm{NS}}$ \\
\hline$\geq 60$ years & $120.5 \pm 11.7$ & $124.5 \pm 10.7$ & $130 \pm 10.7$ & $0.1 *^{\mathrm{NS}}$ \\
\hline
\end{tabular}

*One way ANOVA test, ${ }^{\text {NS }}$ Not significant. 
The potassium level was significantly decreased one hour after nebulizer administration for both males and females patients $(p=0.05, p=0.04)$. The RBS mean was not significantly changed after one hour after nebulizer administration for both males and females patients, so both genders had same electrolyte and glucose heamostasis (Table 6).

Table 6. Distribution of potassium and RBS means according to three measurements for both gender

\begin{tabular}{lllll}
\hline Variable & Baseline & After 30 minutes & After 1 hour & P \\
\cline { 2 - 4 } & Mean \pm SD & Mean \pm SD & Mean \pm SD & $0.05^{* \mathrm{~S}}$ \\
\hline Potassium & & & $0.04^{* \mathrm{~S}}$ \\
Male & $4.55 \pm 0.69$ & $4.37 \pm 0.65$ & $4.22 \pm 0.64$ & $0.08^{* \mathrm{NS}}$ \\
Female & $4.59 \pm 0.68$ & $4.41 \pm 0.71$ & $4.24 \pm 0.74$ & $0.07^{\mathrm{NS}}$ \\
Male & $118.4 \pm 19.7$ & $122.7 \pm 19.6$ & $127.5 \pm 19.8$ & $126.5 \pm 16.6$ \\
\hline
\end{tabular}

*One way ANOVA test, ${ }^{\mathrm{S}}$ Significant, ${ }^{\mathrm{NS}}$ Not significant.

Regarding the steroid medication history and it's effect on the study results as it is a common drug used in addition to salbutimol, the potassium level was significantly decreased one hour after nebulizer administration for patients with negative steroids history $(\mathrm{p}=0.03$ ). The RBS level was significantly increased one hour after nebulizer administration for patients with positive steroids history $(\mathrm{p}=0.04)$. The potassium level was not significantly changed one hour after nebulizer administration for patients with positive steroids history, while the RBS level was not significantly changed one hour after nebulizer administration for patients with negative steroids history, so steroid medication plays a role in the effect of salbutamol nebulizer on blood sugar and serum potassium, although it's effect on potassium in patients with positive steroid history was not significantly increased in this study (Table 7).

Table 7. Distribution of potassium and RBS means according to three measurements for steroids history groups

\begin{tabular}{lllll}
\hline Variable & Baseline & After 30 minutes & After 1 hour \\
\cline { 2 - 4 } & Mean \pm SD & Mean \pm SD & Mean \pm SD \\
\hline Potassium & $4.65 \pm 0.73$ & $4.48 \pm 0.7$ & $4.32 \pm 0.68$ & $0.06^{* \mathrm{NS}}$ \\
Positive steroids & $4.48 \pm 0.63$ & $4.3 \pm 0.65$ & $4.1 \pm 0.69$ & $0.03^{* \mathrm{~S}}$ \\
Negative steroids & & & & $0.04^{* \mathrm{~S}}$ \\
\hline RBS & $116.3 \pm 18.3$ & $120.7 \pm 18.4$ & $128.8 \pm 18.1$ & $0.08^{* \mathrm{NS}}$ \\
Positive steroids & $121.1 \pm 17.9$ & $125.3 \pm 17.5$ & $129.2 \pm 18$ & \\
Negative steroids & & & \\
\hline
\end{tabular}

*One way ANOVA test, ${ }^{\text {S }}$ Significant, ${ }^{\text {NS }}$ Not significant.

\section{Discussion}

The nebulizers have an important benefit in the deposition of drugs to the respiratory system directly with lower side effects. Many factors like drugs properties, airways structure, and technique of nebulization and design of nebulizer equipment have a potential effect on nebulizer efficacy (Pandya et al., 2014).

In the present study, the mean potassium level of patients with asthma was significantly reduced after one hour of nebulizer administration $(\mathrm{p}=0.002)$. This finding is similar to results of many literatures like Sahan et al., study in Turkey which was a prospective study included 26 asthmatic patients treated with nebulizer in ED and assessed for serum potassium and phosphate after one hour. They found a significant hypokalemia effect after one hour of administration of nebulized salbutamol. The stimulation of Beta adrenergic agonists is commonly accompanied by 
stimulation of membrane bound sodium-potassium ATPase enzyme which in turn leads to direct potassium influx into cells (Sahan et al., 2013). This rapid decline in Potassium level is aggravated by steroids and diuretics (Johns \& Roberts, 2007). In India, a clinical trial study conducted by Sree et al in emergency department on 30 patients with hyperkalemia treated with nebulized salbutamol for more than 10 minutes and revealed a significant decrease in Potassium level without side effects. They recommended the use of salbutamol nebulizer in the management of hyperkalemia with short duration and monitoring of potassium and glucose levels (Sree \& Rao, 2011). Another study in the UK by Ahee et al reported the significance of nebulized salbutamol in treatment of hyperkalemia patients presented to ED (Ahee \& Crowe, 2000). Many limitations are reported with high dose of salbutamol administration through the nebulizer such as tremor, hypokalaemia, hyperglycemia and tachycardia (Pandya et al., 2014). It was proved that lowering levels of potassium by nebulizer is dose dependant and drug potency dependant (Johns \& Roberts, 2007). Wong et al ${ }^{25}$ reported that the mean decrease of Potassium was different between three Beta adrenergic agonists (fenoterol, salbutamol and terbutaline) (Wong et al., 1998).

Zitek et al randomized clinical trial study in the USA revealed that the use of one hour nebulized salbutamol for healthy people lead to the increase of lactate and decrease in the Potassium level (Zitek et al., 2016).

In Iraq, a study carried out by Marbut MM et al ${ }^{28}$ recommended the use of magnesium sulfate with salbutamol in nebulizers of children and adolescents to increase the efficacy and protective effect with frequent monitoring of potassium and glucose level (Marbut et al., 2008).

Mohammad et al study in Egypt showed that the electrolytes disturbances were present during acute asthmatic attacks but not for Potassium, while for patients with severe persistent asthma, the hypokalemia was significantly proved (Mohammad et al., 2014). Yang et al study in Taiwan alxo revealed that nebulized sabutamol causes hypokalemia (Yang et al., 2000).

Also in the current study, glucose level, was significantly increased after one hour of nebulized salbutamol $(\mathrm{p}=0.006)$. This finding coincides with reports of Sears study in Canada (Sears et al., 2002). which documented that the use of nebulized Beta adrenergic agonists especially salbutamol is accompanied by increase in blood glucose level but regarded this effect as minor for patients except for diabetic patients. However, König et al study in the USA applied salbutamol $2.5 \mathrm{mg}$ by nebulizer for patient group with DM and another patient group with cystic fibrosis and showed no clinically significant difference in blood glucose level for both group from baseline, although the blood glucose level of diabetic patients was significantly higher than blood glucose level of cystic fibrosis patients (König et al., 2005).

In a multi-systemic review study carried out by Camargo et al reported that continuous use of Beta adrenergic agonists by asthmatic patients was significantly associated with tremor but with no significant changes in Potassium and blood glucose levels (Camargo et al., 2003).

In the UK, Smith et al recruited 25 severe asthmatic patients treated with salbutamol and found that after 24 hours of treatment, the blood glucose and insulin levels were increased. The increase in the insulin in the first 24 hours was not enough to normalize the blood glucose level while in second the 24 hours, the glucose homeostasis returned tu normal (Smith et al., 1998).

Our study showed no significant effect of patients' age on blood levels of potassium and glucose after administration of nebulized salbutamol. This finding is similar to results of Dickens et al study in the USA which reported no significant differences in potassium and glucose for different age groups in asthmatic or COPD patients after treatment with nebulized salbutamol (Dickens et al., 1996). In the present study, the potassium level of patients was significantly decreased after one hour treatment with nebulized salbutamol for both genders. This finding is consistent with results of Sahan et al ${ }^{20}$ in Turkey which stated that the blood glucose level rise after salbutamol nebulization was not significantly different in both genders. This fact may state that the glucose heamostasis is the same in both genders although the ample size was small in both studies (Sahan et al., 2013).

Current study showed that patients with no steroids history had significant decline in potassium level after one hour treatment with nebulized salbutamol $(\mathrm{p}=0.03)$. This finding is in agreement with reports of Ericson-Neilsen et al study in the USA which stated that the corticosteroids had a significant effect on Potassium level which alter the effect of nebulized salbutamol on Potassium level. Inversely, our study found a significant increase in blood glucose level of patients after one hour treatment with nebulized salbutamol if accompanied with positive steroids history (Ericson \& Kaye, 2014).

\section{Conclusions}

1) The nebulizer applying salbutamol has a profound effect in lowering the serum potassium level and increasing blood glucose level after 60 minutes of administration. 
2) The effect of nebulizer in lowering serum potassium level is equal in both genders.

3) The effect of nebulizer in lowering serum potassium level is attenuated with corticosteroid intake.

\section{Recommendations}

1) Care and close monitoring must be taken in consideration during treatment of elderly patients with nebulized salbutamol especially those with heart diseases.

2) Studies on diabetic patients are recommended.

\section{Competing Interests Statement}

The authors declare that there are no competing or potential conflicts of interest.

\section{References}

Ahee, P., \& Crowe, A. V. (2009). The management of hyperkalaemia in the emergency department. Emergency Medicine Journal, 17, 188-191. https://doi.org/10.1136/emj.17.3.188

Andersson, D. C., Betzenhauser, M. J., Reiken, S., Umanskaya, A., Shiomi, T., \& Marks, A. R. (2012). Stress-induced increase in skeletal muscle force requires protein kinase A phosphorylation of the ryanodine receptor. Journal of Physiology-London, 590(24), 6381-6387. https://doi.org/10.1113/jphysiol.2012.237925

Ari, A. (2014). Jet, Ultrasonic, \& Mesh Nebulizers. An Evaluation of Nebulizers for Better Clinical Outcomes. Eurasian Journal of Pulmonology, 16, 1-7. https://doi.org/10.1152/physrev.00011.2003

Bennett, J. A., \& Tattersfield, A. E. (2000). Time course and relative dose potency of systemic effects from salmeterol and salbutamol in healthy subjects. Thorax, 52(5), 458-464. https://doi.org/10.1136/thx.52.5.458

Camargo Jr, C. A., Spooner, C., \& Rowe, B. H. (2003). Continuous versus intermittent beta-agonists for acute asthma. Cochrane Database of Systematic Reviews, (4), Art. No.: CD001115. https://doi.org/10.1002/14651858.CD001115

Cazzola, M., Calzetta, L., \& Matera, M. G. (2011). $\beta 2$-adrenoceptor agonists: current and future direction. British Journal of Pharmacology, 163(1), 4-17. https://doi.org/10.1111/j.1476-5381.2011.01216.x

Cazzola, M., Page, C. P., Calzetta, L., \& Matera, M. G. (2012). Pharmacology and Therapeutics of Bronchodilators. Pharmacological Reviews; 64(3), 450-504. https://doi.org/10.1124/pr.111.004580

Clausen, T. (2003). Na+-K+ pump regulation and skeletal muscle contractility. Physiological Reviews, 83(4), 1269-1324. https://doi.org/10.1152/physrev.00011.2003

Dessanges, J. F. (2001). A history of nebulization. $J$ Aerosol Med, 14(1), 65-71. https://doi.org/10.1089/08942680152007918

Dickens, G. R., McCoy, R. A., West, R., Stapczynski, J. S., \& Clifton, G. D. (1996). Effect of nebulized albuterol on serum potassium and cardiac rhythm in patients with asthma or chronic obstructive pulmonary disease. Pharmacotherapy, 14(6), 729-733.

Ericson-Neilsen, W., \& Kaye, A. D. (2014). Steroids: Pharmacology, Complications, and Practice Delivery Issues. The Ochsner Journal, 14(2), 203-207.

Holt, T. (2007). Inhaled Beta Agonists. Respiratory Care, 52(7), 820-832.

Hostrup, M., Kalsen, A., Ørtenblad, N., Juel, C., Mørch, K., Rzeppa, S., Karlsson, S., Backer, V., \& Bangsbo, J. (2014). Beta2-adrenergic stimulation enhances $\mathrm{Ca} 2+$ release and contractile properties of skeletal muscles, and counteracts exercise-induced reductions in $\mathrm{Na}+/ \mathrm{K}+$-ATPase Vmax in trained men. The Journal of Physiology. https://doi.org/10.1113/jphysiol.2014.277095

Johns, R., \& Roberts, M. (2007). Nebulisers: their effectiveness, indications and limitations. Prescriber, 16-26. https://doi.org/10.1002/psb.18

Johnson, M. (2001). Beta2-adrenoceptors: mechanisms of action of beta2 agonists. Paediatric Respiratory Reviews, 2(1), 57-62. https://doi.org/10.1053/prrv.2000.0102

Kalsen, A., Hostrup, M., Karlsson, S., Hemmersbach, P., Bangsbo, J., \& Backer, V. (2014). Effect of inhaled terbutaline on substrate utilization and 300-kcal time trial performance. $J$ Appl Physiol. https://doi.org/10.1152/japplphysiol.00635.2014

König, P., Goldstein, D., Poehlmann, M., Rife, D., Ge, B., \& Hewett, J. (2005). Effect of nebulized albuterol on blood glucose in patients with diabetes mellitus with and without cystic fibrosis. Pediatr Pulmonol; 40(2), 
105-108. https://doi.org/10.1002/ppul.20263

Levy, B., Desebbe, O., Montemont, C., \& Gibot, S. (2008).Increased aerobic glycolysis through $\beta 2$ stimulations is a common mechanism involved in lactate formation during shock. Shock, 30(4), 417-421. https://doi.org/10.1097/SHK.0b013e318167378f

Máiz Carro, L., \&Wagner Struwing, C. (2011). Benefits of nebulized therapy: basic concepts. Arch Bronconeumol, 47(Suppl 6), 2-7. https://doi.org/10.1016/S0300-2896(11)70028-X

Marbut, M. M., Sadoon, I. R., \& Al-Jubori, A. A. (2008). Evaluation the role of nebulized magnesium sulfate in the treatment of severe exacerbation of asthma in children \& adolescence. Tikrit Medical Journal, 14(2), 1-9.

Mohammad, H. A., Abdulfttah, M. T., Abdulazez, A. O., Mahmoud, A. M., \& Emam, R. M. (2014). A study of electrolyte disturbances in patients with chronic stable asthma and with asthma attacks. Egyptian Journal of Chest Diseases and Tuberculosis, 63(3), 529-534. https://doi.org/10.1016/j.ejcdt.2014.03.010

Ouf, F. M., Abdel Aziz, A. F., Wahba, A. H., Kabil, A. E., \& Alhusseiny, M. A. (2015). Electrolyte disturbances and their impact on mechanically ventilated patients with acute exacerbation of chronic obstructive pulmonary disease. $A A M J, 13(4), 27-34$.

Pandya, D., Puttanna, A., \& Balagopal, V. (2014). Systemic Effects of Inhaled Corticosteroids: An Overview. The Open Respiratory Medicine Journal, 8, 59-65. https://doi.org/10.2174/1874306401408010059

Sahan, M., Yılmaz, M., Gokel, Y., Erden, E. S., \& Karakus, A. (2013). Nebulized salbutamol for asthma: Effects on serum potassium and phosphate levels at the $60 \mathrm{~min}$. Revista Portuguesa de Pneumologia, 19(5), 200-203. https://doi.org/10.1016/j.rppneu.2012.12.003

Scichilone, N., Ventura, M. T., \& Bonini, M. (2015). Choosing wisely: practical considerations on treatment efficacy and safety of asthma in the elderly. Clinical and Molecular Allergy: CMA, 13(1), 7. https://doi.org/10.1186/s12948-015-0016-x

Sears, M. R. (2002). Adverse effects of $\beta$-agonists. Journal of Allergy and Clinical Immunology, 110(6), S322-S328. https://doi.org/10.1067/mai.2002.129966

Sears, M. R., \& Lötvall, J. (2005). Past, present and future--beta2-adrenoceptor agonists in asthma management. Respiratory Medicine, 99(2), 152-170. https://doi.org/10.1016/j.rmed.2004.07.003

Smith, A. P., Banks, J., Buchanan, K., Cheong, B., \& Gunawardena, K. A. (1998). Mechanisms of abnormal glucose metabolism during the treatment of acute severe asthma. $Q J \mathrm{Med}, 82(297), 71-80$.

Sree, N. K., \& Rao, R. N. (2011). Salbutamol nebulization in treatment of hyperkalemia. IJPBS, 2(4), 104-118.

Tank, A. W., \& Lee, W. D. (2015). Peripheral and central effects of circulating catecholamines. Comprehensive Physiology, 5(1), 1-15. https://doi.org/10.1002/cphy.c140007

Wong, C. S., Pavord, I. D., \& Williams, J. (1998). Bronchodilator, cardiovascular, and hypokalaemic effects of fenoterol, salbutamol, and terbutaline in asthma. Lancet, 336, 1396-1399. https://doi.org/10.1016/0140-6736(90)93099-B

Wright, J., Brocklebank, D., \& Ram, F. (2002). Inhaler devices for the treatment of asthma and chronic obstructive airways disease (COPD). Quality \& safety in health care, 11(4), 376-382. https://doi.org/10.1136/qhc.11.4.376

Yang, C. T., Lin, H. C., Lin, M. C., Wang, C. H., Lee, C. H., \& Kuo, H. P. (2000). Effect of beta 2-adrenoceptor agonists on plasma potassium and cardiopulmonary responses on exercise in patients with chronic obstructive pulmonary disease. Eur J Clin Pharmacol, 49(5), 341-345. https://doi.org/10.1007/BF00203774

Zitek, T., Cleveland, N., Rahbar, A., Parker, J., Lim, C., Elsbecker, S., Forred, W., \& Slattery, D. E. (2016). Effect of Nebulized Albuterol on Serum Lactate and Potassium in Healthy Subjects. Acad Emerg Med, 23(6), 718-721. https://doi.org/10.1111/acem.12937

\section{Copyrights}

Copyright for this article is retained by the author(s), with first publication rights granted to the journal.

This is an open-access article distributed under the terms and conditions of the Creative Commons Attribution license (http://creativecommons.org/licenses/by/4.0/). 